\title{
Selecting Bus Stops for Accessibility Improvements for Riders with Physical Disabilities
}

\author{
Wanyang Wu, Albert Gan, Fabian Cevallos, and L. David Shen \\ Florida International University
}

\begin{abstract}
Bus stops are key links in the journeys of riders with disabilities. Inaccessible bus stops prevent people with physical disabilities from using fixed-route bus services, thus limiting their mobility. Due to limited budgets, transit agencies must select bus stops for which their improvements, as part of the effort to comply with the Americas with Disabilities Act (ADA), can maximize the overall benefits to riders with physical disabilities. In this paper, an analytic hierarchy process (AHP) was applied to combine the factors affecting the benefits to riders with physical disabilities, and a binary linear programming model was used to identify bus stops for ADA improvements based on budgetary and construction cost constraints. As an application example, the optimization model was applied to the 5,034 bus stops in Broward County, Florida. Compared to the usual approaches, the optimization model provides a more objective platform on which to identify bus stops for ADA improvements.
\end{abstract}

\section{Introduction}

Bus stops are key links in the journeys of bus riders and are, therefore, a critical factor in evaluating the efficiency of a bus transit system. Because of physical, sensory, or mental difficulties, people with disabilities often rely on public transit as their primary source of transportation. However, inaccessible bus stops, as a result 
of poor design, physical barriers, topographical conditions, or lack of a sidewalk infrastructure, prevent riders with physical disabilities from using fixed-route bus services. Inaccessible bus stops can limit the mobility of people with physical disabilities, lower the efficiency of public transit, and encourage riders to use other transit services such as paratransit, which are more expensive to operate.

Accessible design generally focuses on compliance with laws and regulations as well as state or local building codes. The laws and regulations are intended to eliminate certain physical barriers that limit the usability of the built environment for people with disabilities. The Americas with Disabilities Act (ADA) of 1990 prescribes the minimum requirements for bus stop accessibility by riders with disabilities. Although the accessibility improvements mandated under the ADA have enforceable regulations and standards, many bus stops still have not met the minimum ADA standards (National Council on Disability 2004). For example, the results from the bus stop maintenance database in Broward County, Florida, show that, by 2006, only 51 percent of its bus stops met the minimum ADA standards.

Obviously, one way for transit agencies to meet the ADA requirements is to add to every bus stop ADA-compliant features such as curb cuts, sidewalks, loading pads, etc. However, due to limited budgets, transit agencies can select only a limited number of bus stops for ADA improvements each year. How best to select bus stops for ADA improvements is the focus of this paper.

In practice, many factors can affect the decision. They may include the spatial distribution of riders with physical disabilities, transit ridership, wheelchair ridership, customer complaints, facility deployment costs, service area demographic information, etc. Most of these factors are related to geography, and each factor has its own evaluation standards. An optimization process can help take into account these factors objectively and determine the best locations for ADA accessibility improvements.

This paper introduces an optimization model developed to help transit agencies to identify a priority list of bus stops for annual ADA accessibility improvements. The model aims to maximize the overall benefits to riders with physical disabilities within the constraint of an annual available budget. The next section introduces the bus stop accessibility standards. The overall methodology for the model development is then described. This is followed by the acquisition and integration of data for the factors considered, and, subsequently, the formulation and evaluation of the optimization model. 


\section{Bus Stop Accessibility Standards}

The ADA is the most important design reference for transit stop inventories, as it outlines the minimum requirements for bus stop accessibility by people with disabilities. Title II of the ADA covers sidewalk and street construction and transit accessibility, referencing the ADA Accessibility Guidelines (ADAAG) or the Uniform Federal Accessibility Standards (UFAS) for new construction and alterations undertaken by or on behalf of a state or local government (Federal Transit Administration 1992). In addition, the Department of Justice (1994) Title II regulation specifically requires that curb ramps are provided when sidewalks or streets are newly constructed or altered.

Figure 1 illustrates the ADA minimum requirements for bus stop accessibility. Based on practical experience of transit agencies (Transit Cooperative Research Program 1996), $5 \mathrm{ft}$ is the preferred width for sidewalks for accommodating patrons with physical disabilities as opposed to the typically-used 3-ft clear passage width. This is because $5 \mathrm{ft}$ of sidewalk is the actual construction width, and some acceptable roadway facilities such as utility poles often occupy the clear width within the sidewalk's area. According to the minimum ADA requirements and the Design Handbook for Florida Bus Passenger Facilities (Florida Planning and Development Lab 2004), 5-ft sidewalks (with a 3 -ft clear accessible route), with existing curb cuts and a $5 \times 8 \mathrm{sq} \mathrm{ft}$ loading pad are the standards for all bus stops.

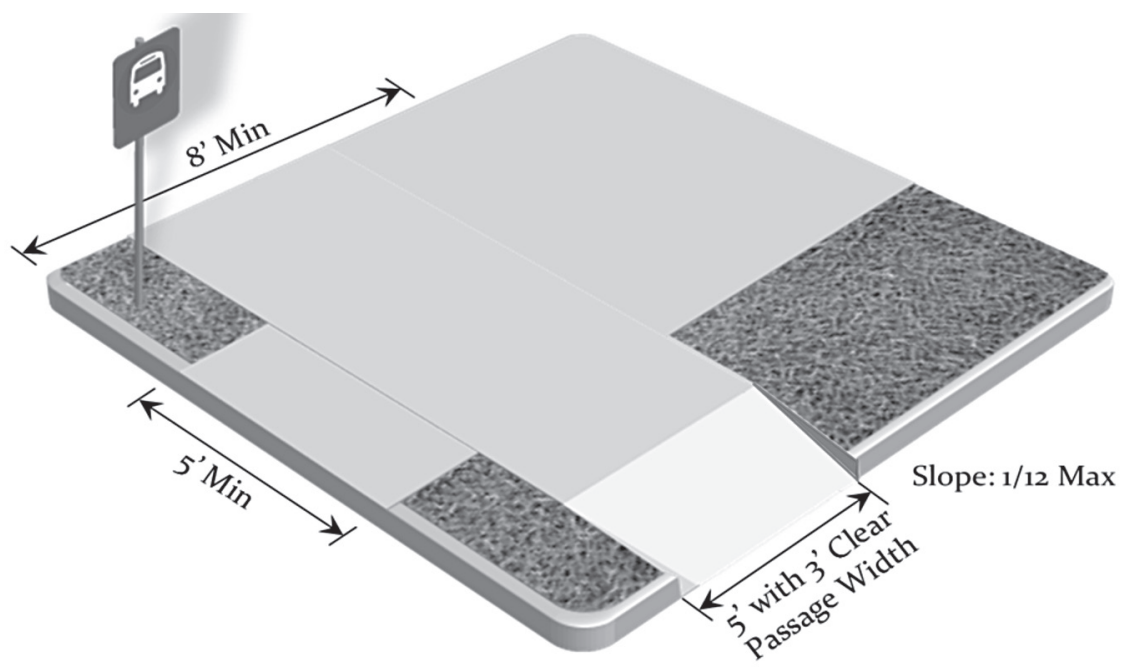

Figure 1. Bus stop design to meet minimum ADA requirements. 


\section{Methodology Overview}

In this paper, the optimization model for determining locations for bus stop accessibility improvements is developed under the framework of spatial multicriteria decision making (MCDM) - an application of multicriteria analysis in a spatial context. MCDM (Thill 1999) has been applied since the development of GIS in the late 1980s and early 1990s. Banai (2000), for example, developed a prototype that integrated GIS with an expert system to assess light rail transit stops with multiple criteria. Additionally, Zhu et al. (2005) developed a GIS-integrated multicriteria analysis model to evaluate accessibility for a housing development in Singapore. The analysis involved a number of criteria related to the convenient access of public transport facilities and amenities, with local residents polled to determine which criteria should be given priority. Eldrandaly et al. (2005) developed a strategy to integrate GIS and analytical hierarchy process analysis (AHP) by using Component Object Model (COM), two major tools commonly used in solving spatial decisionmaking problems. As mentioned, many factors can affect optimum bus stop investment decisions. The spatial attributes of bus stops and geographic factors make spatial MCDM an ideal means by which to build decision tools for bus stop facilities allocation.

As the first step in the optimization model development, a bus stop accessibility checklist based on ADA minimum requirements is created. After the checklist specifying each minimum ADA requirement is established, a bus stop inventory with detailed bus stop features for each bus stop is then used to compare against the checklist to determine if a bus stop meets the minimum ADA requirements and what additional features must be installed to make the stop ADA-compliant.

The next step is to select the factors that will serve as the surrogate measures of benefits to riders with physical disabilities. The benefits to riders with physical disabilities reflect the level of potential for a bus stop selected for ADA improvements to meet the greatest need of those riders with additional accessibility requirements. Bus stop, transit ridership, and socioeconomic data from three main sources then are collected. As an application example, data from Broward County Transit (BCT) are used. BCT possesses a comprehensive bus stop inventory, a detailed ridership at the bus stop level, various GIS maps that include bus routes and bus stops improvements, and budgetary information. In addition, the 2000 Census offers information on the spatial distribution and types of populations with disabilities. These will be described in more detail in the next section. 
AHP, which is an MCDM technique, then is used to (1) combine different factors for prioritizing, ranking, and evaluating alternatives; (2) compare and evaluate different criteria such as the distribution of persons with physical disabilities, ridership, and land use; and (3) assign weights to bus stops.

A binary linear programming model then is formulated. Within the constraint of a given budget for ADA improvements, the model aims to select bus stops for which the improvements will maximize the total benefit to riders with physical disabilities. The benefits are measured based on the scores derived through AHP for the individual candidate bus stops. The model is formulated such that all selected bus stops can be brought into full compliance with minimum ADA accessibility standards. In other words, the process will not output decisions to add features to bus stops that do not result in full ADA compliance.

\section{Data Preparation}

\section{Budget and Cost Estimates}

Budgetary information was mainly derived from the Broward County Transit Development Plan (Broward County Transit 2005) and the Broward County Metropolitan Planning Organization Transportation Improvement Program. The assigned budget for transit ADA improvements is $\$ 2.0$ million per year between the years 2006 and 2010.

Cost calculations for ADA bus stop improvements cannot assure that the projected cost will be exactly the same as that for the actual construction work. Construction costs vary with different contractors, and costs with regard to bus stop improvements likely will change during construction, due to inflation or other unforeseen factors. Accordingly, this study can make only reasonable cost estimates for each bus stop. Design, maintenance of traffic, and construction usually make up the general cost of improvements. Sidewalk length was considered the sidewalk distance from the bus stop to the nearest intersection. Table 1 gives the costs for different facilities with regard to ADA improvements at bus stops. In sum, minimum ADA improvement concentrated on sidewalks, loading pads, and curb cuts. Based on the cost information and the existing stop inventory, the total cost required to meet the minimum ADA standards for each bus stop was calculated and available for use in the optimization model to be described next. 
Table 1. Cost Estimates of ADA Bus Stop Improvements

\begin{tabular}{|l|l|r|}
\hline ADA Bus Stop Improvement Type & Unit & Unit Price \\
\hline Maintenance of Traffic & Each & $\$ 500.00$ \\
\hline Concrete material and installation (6") thick, 1-500 SF & Square Foot & $\$ 13.75$ \\
\hline Concrete material and installation (6") thick, 501-1000 SF & Square Foot & $\$ 8.25$ \\
\hline Concrete material and installation (6") thick, 1001-9000 SF & Square Foot & $\$ 8.00$ \\
\hline Subgrade Preparation for Concrete Pour & Square Yards & $\$ 2.00$ \\
\hline Curb Cuts, Drawing I & Each & $\$ 800.00$ \\
\hline Concrete removal & Square Foot & $\$ 4.50$ \\
\hline Curb removal & Foot & $\$ 11.00$ \\
\hline
\end{tabular}

\section{Bus Stop Inventory and Ridership}

BCT possesses a bus stop inventory that includes data on 5,034 bus stops serving 43 different bus routes. The inventory includes all of the bus stop facilities' information and ADA accessibility status. There were 1,616 bus stops designated as not fully accessible and 849 as inaccessible for people with physical disabilities, for a total of 2,465 bus stops (49\%) that do not meet the minimum ADA requirements. "Not fully accessible stops" are stops that do not fully comply with the ADA requirements, yet can be accessed by people with physical disabilities. Figure 2 shows the current bus stop distribution in Broward County, where dark nodes represent $A D A$-incompliant bus stops and white nodes represent ADA-compliant bus stops.

Because some bus routes cross the county boundary into the neighboring MiamiDade and Palm Beach counties, a quarter-mile radius buffer along those routes has been developed to maintain the integrity of the entire bus stop system. It is easy to see that ADA-incompliant bus stops pervade the whole bus stop system. Since $1996, B C T$ has been in the process of improving the accessibility of bus stops, with a target of making 300-500 additional bus stops accessible each year. BCT also provides Automatic Passenger Counter (APC) datasets that could be used to weigh the importance of accessibility for bus stops. The dataset includes the ridership based on bus stop IDs, which were collected from May 2008 through September 2008. 


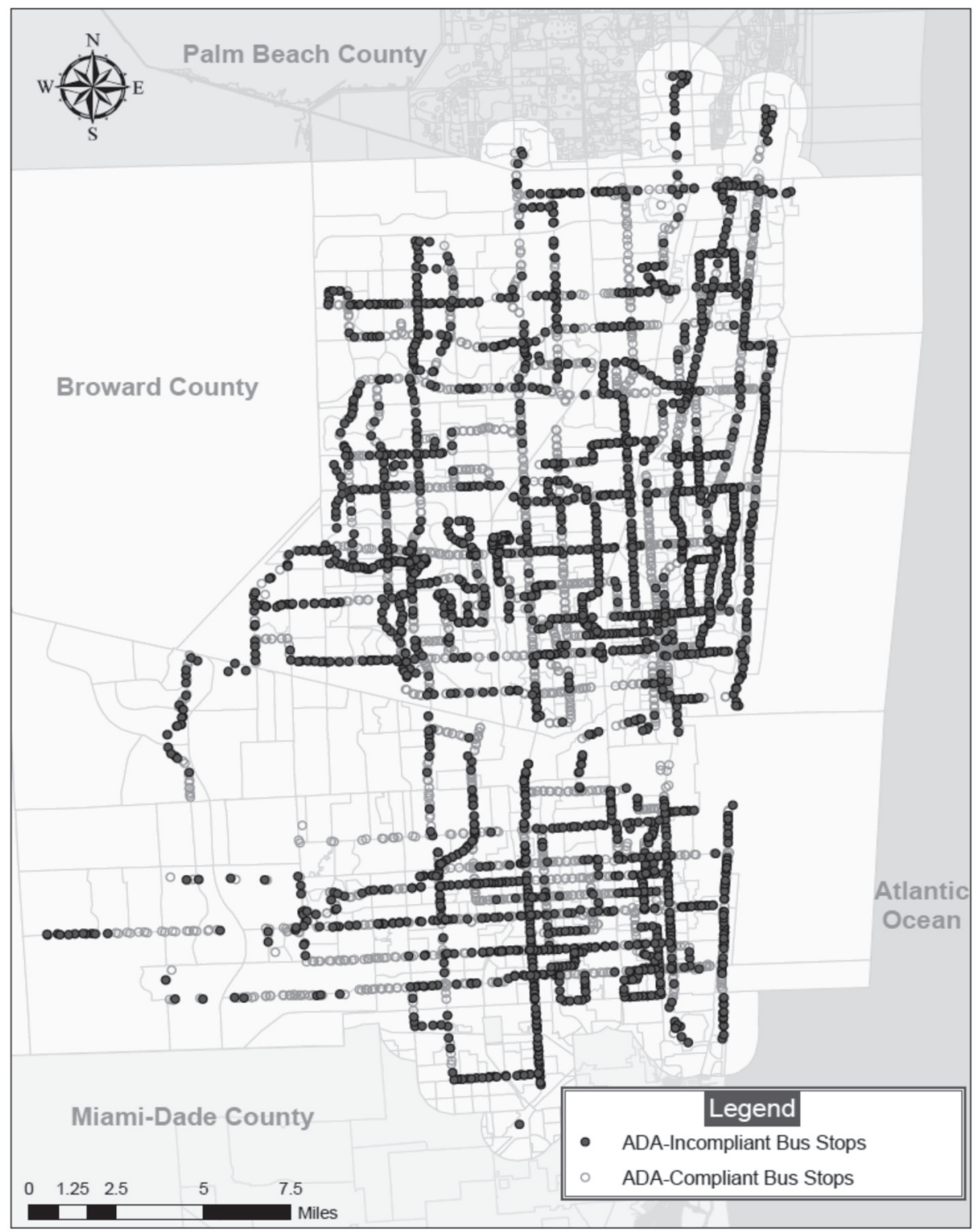

Figure 2. ADA status of bus stops of Broward County Transit. 


\section{Data for Demographic and Other Factors}

The location(s) of the population with physical disabilities is the most important factor in deciding bus stop ADA improvements. Obviously, those areas that have a greater percentage of persons with physical disabilities deserve to have higher quality transit services. Hence, the population with physical disabilities $5+$ years of age was extracted from the 2000 Census Summary Tape File \#3. Apart from the original locations of the population with physical disabilities, several surveys and studies (Collia 2003, Scottish Executive Social Research 2006, U.S. Department of Transportation 2003) have been undertaken to examine the travel patterns of people with physical disabilities who use public transit to establish which bus stops are near common destinations. These bus stops should get priority for ADA accessibility improvements. Work-related place, school, health care facilities, and shopping centers (including supermarkets) should be treated as common destinations for people with physical disabilities. Census Transportation Planning Package (CTPP) 2000 provided the data regarding ridership to work by bus for the population with physical disabilities based on Traffic Analysis Zones (TAZ). The Florida Geographic Data Library (FGDL) provides GIS layers of school, health care facilities, and shopping centers for the weighting of bus stops. Table 2 shows a detailed description of the data.

Table 2. GIS Layers and Data Sources

\begin{tabular}{|l|l|l|l|l|}
\hline Content Title & Source & $\begin{array}{l}\text { Feature } \\
\text { Type }\end{array}$ & Extent & $\begin{array}{l}\text { Data } \\
\text { Years }\end{array}$ \\
\hline Population with Physical Disabilities & US Census Bureau & polygon & $\begin{array}{l}\text { Broward } \\
\text { County }\end{array}$ & 2000 \\
\hline Ridership per Stop & $\begin{array}{l}\text { Broward County } \\
\text { Transit }\end{array}$ & dBASE & $\begin{array}{l}\text { Broward } \\
\text { County }\end{array}$ & $\begin{array}{l}05 / 2008- \\
09 / 2008\end{array}$ \\
\hline $\begin{array}{l}\text { Work Trips by People with Physical } \\
\text { Disabilities }\end{array}$ & $\begin{array}{l}\text { Census } \\
\text { Transportation } \\
\text { Planning Package }\end{array}$ & polygon & $\begin{array}{l}\text { Broward } \\
\text { County }\end{array}$ & 2000 \\
\hline Schools & UF GeoPlan Center* & point & State & 2008 \\
\hline Health Care Facilities & UF GeoPlan Center & point & State & 2005 \\
\hline Shopping Centers & UF GeoPlan Center & point & State & 2003 \\
\hline
\end{tabular}

*University of Florida GeoPlan Center 


\section{Data Extraction and Integration}

To study the service scale of bus stops, the service buffer area based on the actual street network is introduced for this analysis. With ArcGIS Network Analyst, the service areas around any location can be built on a region that encompasses all accessible streets (i.e., streets that are within specified impedance), called a network service area. For instance, the five-minute service area for a given point includes all the streets that can be reached within five minutes from that point. Because a standard for the minimum walking distance to transit stops for people with physical disabilities cannot be found in the literature, this paper assumes the standard quarter-mile walking distance that is usually used for the general population.

A VBA script was developed using ESRI's ArcObjects preceding the combination and joining of the data. Buffer zones were created as well. As shown in Figure 3, the process involves the following five steps:

1. Filter the original bus stop database against ADA accessibility standards to determine candidate bus stops that need accessibility improvements.

2. Create a service area based on the quarter-mile walking distance around every candidate bus stop.

3. Combine the ridership and candidate bus stop databases based on bus stop IDs.

4. Calculate the population with physical disabilities, work trips by people with physical disabilities, the number of schools, the number of health care facilities, and the number of shopping centers within each service area.

5. Apply the combined database in an analytical hierarchy process (AHP) analysis.

As mentioned, the AHP is an MCDM technique that can combine different factors for prioritizing, ranking, and evaluating alternatives (Malczewski 1999). In this paper, AHP was used to compare and evaluate the different criteria within every candidate bus stop buffer zone. Six factors considered: 1) distribution of the population with physical disabilities, 2) ridership, 3) work trips by people with physical disabilities, 4) health care facilities, 5) schools, and 6) shopping centers. These criteria were then assigned weights based on their relative importance. 


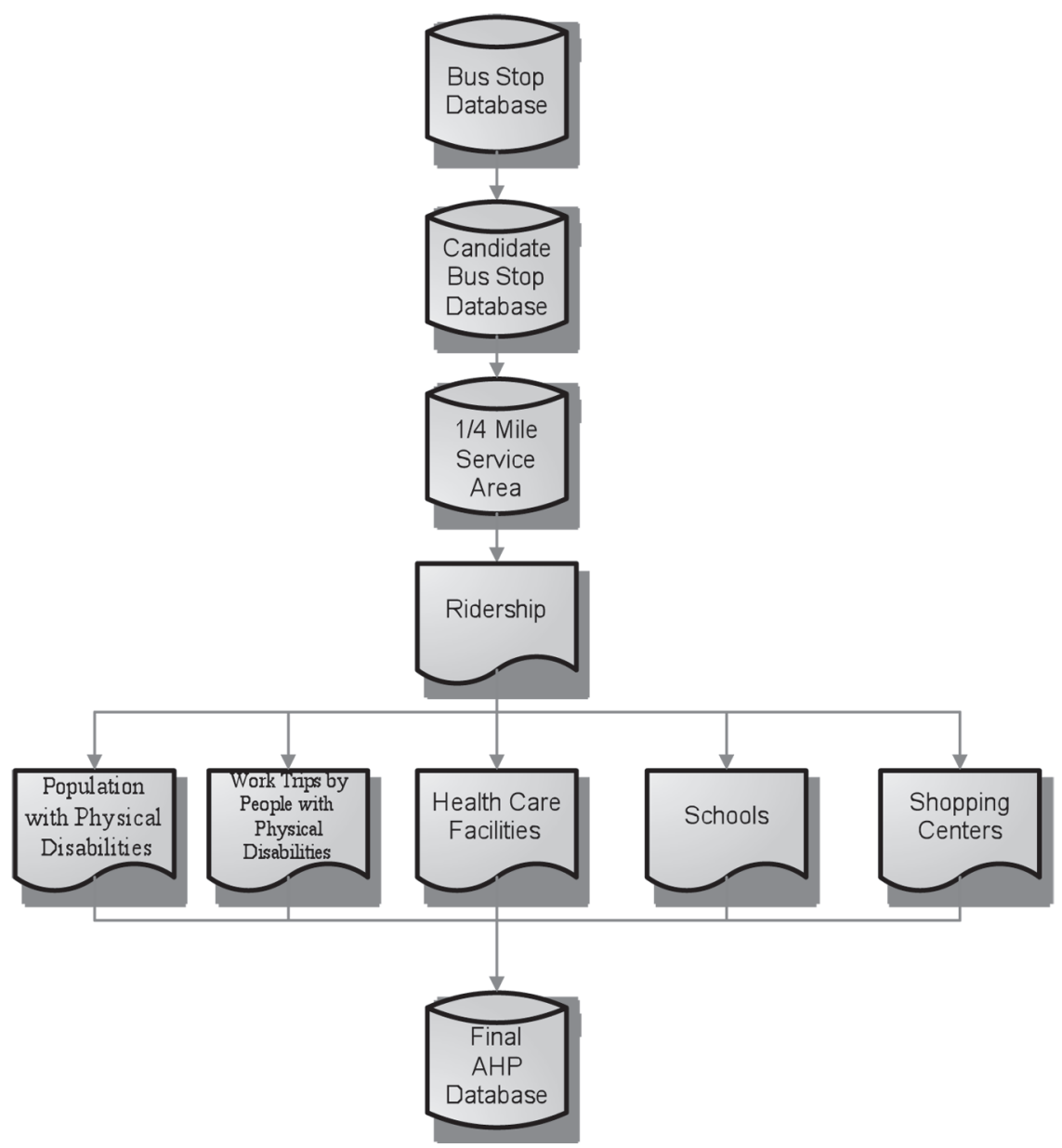

Figure 3. Data integration framework.

The AHP process consists of three steps as described here.

\section{Step 1: Standardizing Factors}

The raw score of each factor for each candidate bus stop was first standardized using the equation below:

$$
x_{i j}^{\prime}=\frac{x_{i j}}{x_{j}^{\max }}
$$


where:

$x_{i j}^{\prime}$ is the standardized score for candidate bus stop $i$ for criterion $j$,

$x_{j}^{\max }$ is the maximum score for criterion $j$, and

$x_{i j}$ is the raw score for candidate bus stop $i$ for criterion $j$.

The benchmark score $\left(x_{j}^{\max }\right)$ was used to compare the scores among the candidate bus stops. $x_{j}^{\max }$ is the maximum score among the bus stops that did not meet the minimum ADA standards based on factor $j$.

\section{Step 2: Weighting Standardized Factor}

The AHP uses composite weights to represent ratings of alternatives with respect to an overall goal. The weights, also referred to as decision alternative scores, are the basis for making decisions. They serve to rate the effectiveness of each alternative in achieving the goal. The overall score for a candidate bus stop is defined as follows:

$$
R_{i}=\sum_{j} w_{j} x_{i j}^{\prime}
$$

where:

$R_{i}$ is the overall score of candidate bus stop $\mathrm{i}$, and

$w_{j}$ is the vector of priorities associated with factor $\mathrm{j}, \sum w_{j}=1$.

Note that $w_{j}$ is an important factor in AHP. It requires assessing the relative importance of different factors, and different assigned $w_{j}$ will result in different output selections. Hence, $w_{j}$ is usually assigned by an experienced transit planner. The default weight used for each factor shown in Table 3 is derived from the survey on travel patterns and percentage of riders with physical disabilities (15). Given that bus stop service areas that have higher populations with physical disabilities necessitate meeting ADA accessibility service requirements directly, residential locations in areas that have a high population of people with physical disabilities should receive the highest weight. Ridership represents the number of boardings for each bus stop; hence, this number was considered the second most important factor. Although the locations of schools, health care facilities, shopping centers, and the work trips by people with physical disabilities are not directly related to the boardings at every bus stop, they have the potential to attract riders as common origins and destinations. These four factors were considered in the process, with each given a lower weight than the first two factors. 
Table 3. Weights Used for Different Factors

\begin{tabular}{|l|c|}
\hline Factors & Weights $\left(w_{j}\right)$ for Minimum ADA Standards \\
\hline Population with Physical Disabilities Location & 0.30 \\
\hline Ridership per Stop & 0.20 \\
\hline Work Trips by People with Physical Disabilities & 0.16 \\
\hline Schools & 0.12 \\
\hline Health Care Facilities & 0.11 \\
\hline Shopping Centers & 0.11 \\
\hline
\end{tabular}

\section{Step 3: Standardizing Weighted Factor}

The overall score Ri from the second step was further standardized for all six factors using the equation below:

$$
R_{i}^{\prime}=\frac{R_{i}}{\sum R_{i}}
$$

$R_{i}^{\prime}$ is the standardized overall score of candidate bus stop $\mathrm{i}$, and

$R_{i}$ is the overall score of candidate bus stop i.

A VBA program was developed to perform all of the calculations involved in the above three steps. The program produced a final score for each candidate bus stop. The scores serve as one of the two major inputs to the optimization model to be described below. The other major input involves the project budget and construction cost estimates described in the previous section.

\section{Optimization Model}

The main objective for the optimization model is to maximize the overall benefits at the bus stop level (i.e., total $R_{i}{ }^{\prime}$ ) to the riders with physical disabilities. This is achieved by attempting to meet the minimum ADA improvements under the constraints of the budget available for such improvements annually. The analytical hierarchy process (AHP) pre-processes the different factors and generates a single weight for each candidate bus stop. This weight $\left(R_{i}{ }^{\prime}\right)$ then becomes the only standard by which to evaluate a given bus stop's importance, or priority over other stops, regarding accessibility improvements. This method simplifies the final opti- 
mization model such that the objective function is the summation of the $R_{i}{ }^{\prime}$ values of selected bus stops.

Within the constraints of this model, only complete ADA accessibility improvements were allowed for each bus stop. Single improvements, such as only building a loading pad without making other improvements to fully meet the minimum ADA requirements, were not allowed. In other words, the transit agency could either choose to make a candidate bus stop fully ADA accessible by adding all the required improvements, or do nothing to the candidate bus stop. Another constraint stems from the limits of the budget available for ADA improvements. Accordingly, the optimization model is formulated as a binary linear programming model, shown below:

$$
\max \sum_{i=1}^{n} R_{i}^{\prime} y_{i}
$$

Subject to:

$$
\begin{aligned}
& y_{i} \in\{0,1\} \\
& \sum_{i=1}^{n} c_{i} y_{i}<B
\end{aligned}
$$

where:

$R_{i}^{\prime} \quad$ is the standardized overall score of candidate bus stop i,

$y_{i} \quad$ is 1 if candidate bus stop $\mathrm{i}$ is selected for improvements and 0 otherwise,

$n \quad$ is the total number of candidate bus stops,

$c_{i} \quad$ is the required ADA improvement cost based on minimum ADA standards for candidate bus stop $\mathrm{i}$, and

$B \quad$ is the total available budget for ADA improvements.

\section{Model Application and Assessment}

The model was implemented in General Algebraic Modeling System (GAMS), version 2.50 (GAMS Development Corporation 2007). GAMS is specifically designed for modeling linear, nonlinear, and mixed integer optimization problems. Given BCT's total available budget of $\$ 2.0$ million for the next budget year and the associated construction costs, the output from the model shows that a total of 519 bus 
stops will get priority for ADA improvements for the next budget year. The maximum total $R_{i}^{\prime}$ for each stop is $3,521.13$, and the total cost is $\$ 1,999,578$.

Figure 4 shows the bus stops selected for ADA improvements as dark nodes. The figure was compared to the distribution of the population with physical disabilities.

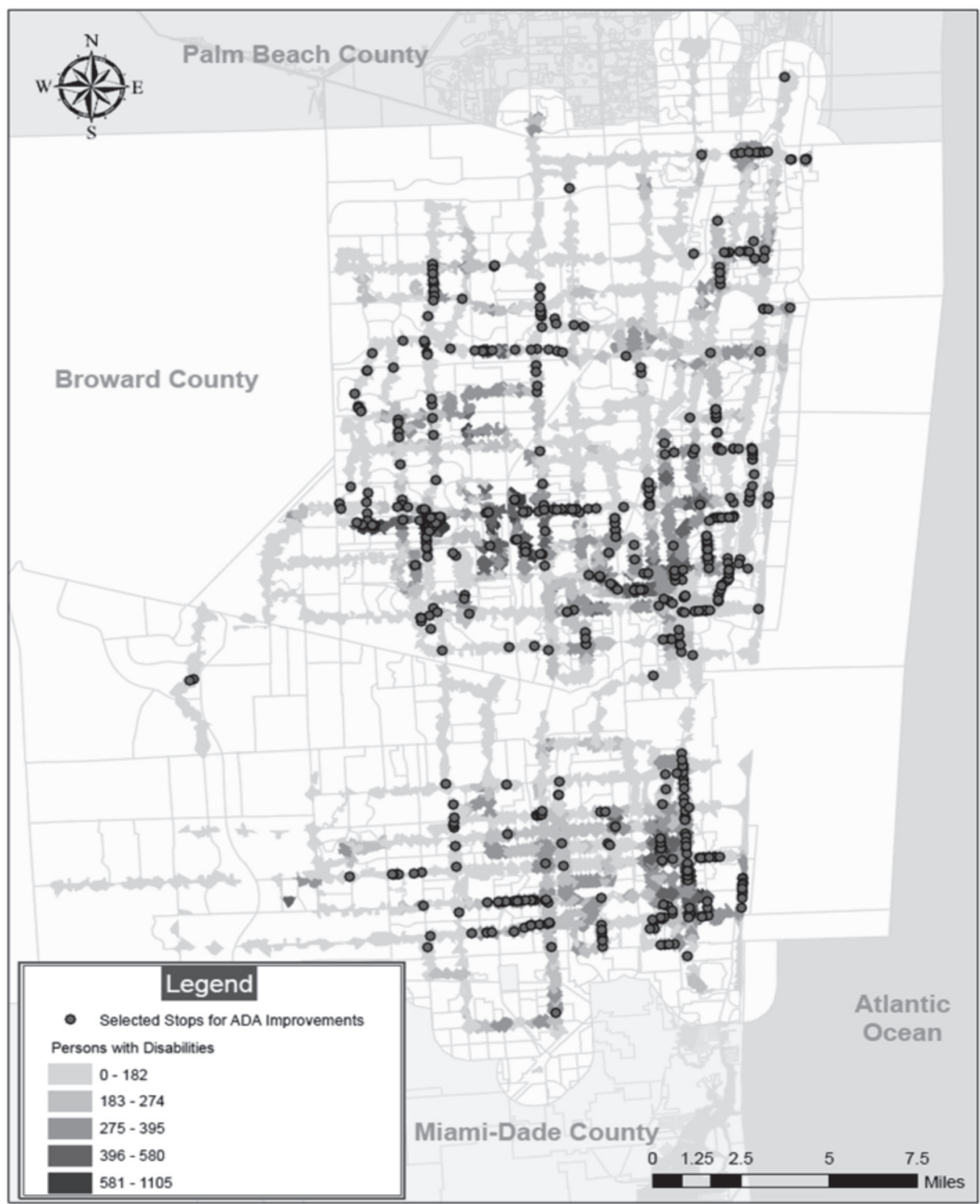

Figure 4. Selected bus stops for ADA improvements. 
The results indicate that the selected bus stops are generally located in those areas with a higher population of physical disabilities density - a factor given the highest weight $\left(w_{j}=0.3\right)$ within the AHP process. The population with physical disabilities averages about 272 people living near the selected bus stops, as compared to an average population with physical disabilities of about 143 for the remaining bus stops. The significance of bus ridership $\left(w_{j}=0.2\right)$ was also reflected in the final map when compared to the ridership database. The average ridership is 951.64 for all the selected bus stops vs. 639.75 for the rest. The selected bus stop locations also were found to match the distribution of health care facilities, schools, and shopping centers.

The model outputs also show that many selected bus stops need only minor investments to provide significant benefits to riders with physical disabilities. The model tends to select bus stops with higher benefit-cost ratios for the current budget year and leaves the bus stops with lower benefit-cost ratios for the next year, so that the maximum total $R_{i}^{\prime}$ and the number of selected bus stops are not the same for each budget year. Note that for practical purposes, it is convenient to organize the work for ADA improvements by grouping bus stops that are close together.

\section{Summary and Conclusions}

In this paper, a binary linear programming optimization model was developed to select bus stops for ADA improvements. In making the selection, the model aims to optimize the benefits to the riders with physical disabilities, given an available annual budget for such improvements. Bus stops from Broward County Transit in Florida were used as an example to describe the model development procedure and its application.

Based on an analysis of the ADA minimum requirements and current bus stop inventory of $B C T$, the construction cost was estimated for every candidate bus stop. The AHP was then used to combine and generate the overall weights for every bus stop, given the different factors. In deriving the data for the factors considered, a quarter-mile walking distance typically used for the general population was used in this research. Future research should attempt to identify other distances that could better reflect conditions for riders with different types of disabilities. A sensitivity analysis should also be performed on these walking distances to assess how the optimization output is impacted. 
The final optimization model showed that approximately 500 bus stops would receive priority ADA improvements and that the selected bus stop locations were consistent with the factors considered. Compared to the usual basis for bus stop improvement selection, such as staff experience or requests from elected officials, this optimization model prioritizes bus stops that are more beneficial to the majority of people with physical disabilities and provides transit agencies with a more objective platform on which to make bus stop improvement suggestions to meet minimum ADA standards.

\section{References}

Banai, R. 2000. "Transit station area land use/site assessment with multiple criteria: An integrated gis-expert system prototype, Journal of Public Transportation 3(1): 95-110.

Broward County Transit. 2005. Broward County Transit Development Plan, http:// www.broward.org/transportationplanning/tpi02601.pdf.

Collia, D. V., J. Sharp, and L. Giesbrecht. 2003. The 2001 National Household Travel Survey: A look into the travel patterns of older Americans," Journal of Safety Research 34: 461- 470.

Eldrandaly, K., N. Eldin, D. Sui, M. Shouman, and G. Nawara. 2005. Integrating GIS and MCDM using COM rechnology, The International Arab Journal of Information Technology 2(2): 163-167.

Federal Transit Administration (FTA). 1992. Accessibility Handbook for Transit Facilities. Malvern, PA.

Florida Planning and Development Lab. 2004. Accessing transit: Design handbook for Florida bus passenger facilities. Florida State University, Tallahassee, FL.

GAMS Development Corporation. 2007. GAMS - A user's guide, http://www.gams. com/docs/gams/GAMSUsersGuide.pdf.

Malczewski, J., 1999. GIS and Multicriteria Decision Analysis. John Wiley \& Sons, Inc., New York.

National Council on Disability. 2004. The current state of transportation for people with disabilities in the United States. Washington, DC. 
Scottish Executive Social Research. 2006. Improved public transport for disabled people, http://www.scotland.gov.uk/Publications/2006/05/16145134/10.

Thill, J., 1999. Spatial Multicriteria Decision Making and Analysis: A Geographic Information Sciences Approach. Ashgate Publishing Ltd, Brookfield, VT.

Transit Cooperative Research Program, 1996. TCRP Report 19: Guidelines for the location and design of bus stops. Washington, DC.

U.S. Department of Transportation. 2003. Freedom to travel. Washington, D.C.

Zhu, X., Liu, S., and Yeow, M. C. 2005. A GIS-based multi-criteria analysis approach to accessibility analysis for housing development in Singapore. The National Biennial Conference of the Spatial Sciences Institute, Melbourne, Australia.

\section{About the Authors}

WaNYANG Wu (wwu@fiu.edu) is a Research Associate with Lehman Center for Transportation Research (LCTR) at Florida International University. He graduated from Florida International University with a Ph.D. in 2009. His interest areas include public transit planning and design, Intelligent Transportation Systems (ITS), traffic operation and safety analysis, traffic simulation, and highway design.

Albert Gan (gana@fiu.edu) is an Associate Professor with the Department of Civil and Environmental Engineering at Florida International University. He received his Ph.D. in Civil Engineering from the University of Florida in 1996. His areas of research include traffic simulation, ITS, transit planning, demand modeling, and highway safety.

Fabian Cevallos (fabian.cevallos@fiu.edu) is a Transit Program Director with Lehman Center for Transportation Research (LCTR) at Florida International University. He received his Ph.D. in Civil Engineering from Florida International University in 2006. His areas of research include Advanced Public Transportation Systems, transit planning and operations, Business Intelligence, and information technology.

L. David Shen (shenl@fiu.edu) is a Professor with the Department of Civil and Environmental Engineering at Florida International University. He received his Ph.D. in Civil Engineering from Clemson University in 1982. His areas of research include highway planning and design, transportation and land development, highway capacity and control systems, mass transit planning, and airport planning and design. 